\title{
A DIVULGAÇÃO DO CONCEITO DE LETRAMENTO E O CONTEXTO DA ESCOLA DE NOVE ANOS: O QUE DIZEM AS PROFESSORAS ALFABETIZADORAS?
}

\author{
Danieli Sebastiana Oliveira Tasca ${ }^{*}$ \\ Ana Lúcia Guedes-Pinto**
}

\begin{abstract}
RESUMO: Este artigo toma o contexto das mudanças recentes deste início do século XXI ocorridas no ensino fundamental: a inclusão das crianças de 6 anos nesse segmento da educação e, consequentemente, a ampliação para nove anos de escolarização fundamental no Brasil. Tais mudanças trouxeram efeitos no modo de organização das escolas. Um deles se mostra na adesão ao currículo ciclado. Outro que se destaca é o investimento das redes de ensino em cursos de formação continuada para seus professores. Tomando como referência uma pesquisa realizada no município de Campinas, estado de São Paulo, que tomou a escuta das professoras dos primeiros anos do ensino fundamental, traz-se para a discussão seus dizeres sobre suas práticas de trabalho. Por meio de suas narrativas podemos nos aproximar do que as professoras afirmam estar trabalhando na escola frente à organização da mesma em ciclos e de como têm elaborado as propostas de ensino da escrita no contexto da divulgação dos estudos do letramento.
\end{abstract}

Palavras-chave: Letramento e formação. Alfabetização e letramento. Narrativas de professores.

* Mestre em Educação e professora alfabetizadora da Rede Municipal de Ensino de Campinas. E-mail: <dani.oliveiratasca@gmail.com>

** Professora livre-docente da Faculdade de Educação da Universidade Estadual de Campinas (Unicamp) e coordenadora do Grupo de Pesquisa Aula - Trabalho Docente na Formação Inicial.E-mail: <alguedes@mpc.com.br>

Disponível em <http://www.cedes.unicamp.br> 
A divulgação do conceito de letramento e o contexto da escola de nove anos...

\title{
THE PRESENTATION OF THE CONCEPT OF LITERACY AND THE CONTEXT OF THE NINE-YEAR EDUCATIONAL PROGRAM: WHAT IS THE OPINION OF LITERACY TEACHERS?
}

\begin{abstract}
This article focuses on the recent changes occurred in the beginning of the $21^{\text {st }}$ century regarding elementary school: the inclusion of six-year-old children in the segment and, consequently, the extension of basic education in Brazil to nine years. Such adjustments had an impact on school organization. One of them is evident by the adoption of the cyclic educational curriculum. Another change is the investment on continuous education for public school teachers. A research accomplished with literacy teachers in Campinas, in Sao Paulo state, brings to the debate their opinion on the working practices. Through their narratives we are able to understand their work in face of the organization of a cyclic educational program and their proposals regarding writing and reading in the context of literacy studies.
\end{abstract}

Key words: Literacy and education. Literacy. Teachers' narratives.

Ensino fundamental de nove anos: outro desenho para a escola

$E$ ste artigo parte das mudanças recentes ocorridas no ensino fundamental: a inclusão das crianças de 6 anos nesse segmento da educação e, consequentemente, a ampliação para nove anos de escolarização fundamental no Brasil. Para esta ampliação, a Lei n. 11.274/2006 alterou o artigo 32 da Lei de Diretrizes e Bases da Educação (LDB, Lei n. 9.394/1996), implantando a matrícula obrigatória de crianças de 6 anos nas escolas de ensino fundamental, tanto nas escolas públicas como nas escolas privadas do país. ${ }^{1}$ Entre os argumentos apresentados pelo Ministério da Educação (MEC), tal mudança apresenta-se como uma possibilidade de ampliação do tempo escolar, em nome da escola de qualidade para todas as crianças das classes populares, ou seja, a alteração no sistema de organização do ensino tem como objetivo a qualificação do ensino-aprendizagem, da alfabetização e do letramento (BRASIL, 2007a).

Como desafio inicial, os professores dos anos iniciais se deparam com uma reconfiguração do ensino. Como mediadores do processo de apropriação da linguagem (tanto da língua portuguesa como da matemática) são responsáveis por valorizar, reconhecer e trabalhar com os saberes das crianças 
que frequentam o $1^{\circ}$ ano do ensino fundamental. Têm a tarefa de organizar o trabalho pedagógico de modo a não repetir as experiências escolares vindas da educação infantil, nem deslocar conteúdos e trabalhos pedagógicos desenvolvidos na antiga primeira série. Isto é, atuar como professor em um primeiro ano do ensino fundamental os coloca em um entrelugar, pois se situam numa posição de transição entre a educação infantil e o início do ensino fundamental.

Kramer (2007) ressalta que, entre os desafios colocados para o ensino fundamental de nove anos, principalmente para o $1^{\circ}$ ano, além de ter que se disponibilizar e adequar fisicamente as salas de aula, de se investir na formação dos profissionais, espera-se dos professores a viabilização do diálogo entre o ensino fundamental e a educação infantil. Para a autora, os direitos sociais das crianças precisam ser assegurados de modo que o trabalho pedagógico leve "[...] em conta a singularidade das ações infantis e o direito à brincadeira, à produção cultural tanto na educação infantil como no ensino fundamental" (p. 20). Ao longo deste artigo, pretendemos discutir os desafios inerentes a essa nova realidade e, por meio dos dizeres dos professores, apresentar possibilidades de desenvolvimento de um trabalho, tendo em vista essa mudança de organização do ensino.

Nesse cenário, as discussões se direcionam para o desafio de elevar a qualidade do ensino e da aprendizagem dos alunos, especialmente do processo de alfabetização. No Brasil, a escolarização obrigatória tem acumulado índices elevados de analfabetismo, tornando ainda visível o fenômeno do fracasso escolar. Os investimentos na ampliação do ensino fundamental e na melhoria da formação inicial e continuada de professores apresentam-se como uma das medidas para reverter esse quadro. Temos visto iniciativas nos âmbitos federal, estadual e municipal quanto ao oferecimento de programas e/ou cursos para os professores.

Em meio a essas mudanças, a organização da escola em ciclos tem sido um dos caminhos propostos por teóricos da área e pelas políticas públicas para a transformação da, até então, escola seriada. Os materiais produzidos pelo MEC para a formação continuada de professores indicam a implantação do ensino fundamental de nove anos e a organização escolar em ciclos. ${ }^{2}$

Freitas (2004a, p. 162), destaca que não basta que os ciclos se contraponham à seriação, alterando tempos e espaços: "É fundamental alterar também o poder inserido nestes tempos e espaços, [...] fazer da escola um tempo de vida e não só de preparação para a vida. Significa permitir que 
A divulgação do conceito de letramento e o contexto da escola de nove anos...

os estudantes construam a vida escolar". O autor destaca o quanto é restrito o poder da escola para mudar o cenário do fracasso. Há muitos limites que estão além dos muros da instituição escolar. Atualmente, identificamos tentativas de reorganização da escola em algumas redes públicas, estaduais ou mesmo municipais, que têm buscado formas alternativas para lidar com as mudanças vindas com o ensino de nove anos. Há propostas e iniciativas de desenvolvimento de experiências inovadoras que nos mostram tanto os limites quanto outras possibilidades. ${ }^{3}$

Propor uma organização escolar por ciclos não depende apenas das concepções de educação dos profissionais, tampouco das políticas públicas que orientam o processo, mas significa opor-se a um determinado tipo de organização que dominou o modelo escolar. Adotar os ciclos de formação não se reduz ao rompimento com a seriação, mas significa opor-se à lógica da exclusão da escola e também a uma lógica sobre o conhecimento e o processo de ensino e de aprendizagem. Nessa perspectiva, a diversidade de experiências dos aprendizes passa a ser a orientadora de tal processo. Sendo assim, ensinar torna-se uma tarefa ainda mais complexa, visto que, para o planejamento do trabalho escolar, é necessário conhecer o que os alunos já sabem e o que eles ainda não sabem sobre a escrita e seu funcionamento, por exemplo.

Nessa nova lógica, a ação docente precisa estar voltada para o que é mais significativo em cada período de formação dos sujeitos, ressalta Dalben (2009). Tal lógica introduz mais um desafio aos professores porque exige que estejam atentos aos ritmos, estilos e tempos diferentes de aprendizagem, de modo que possam articular os conteúdos necessários à aprendizagem escolar no conjunto das açóes desenvolvidas.

Vale ressaltar que esta organização, embora alternativa, também apresenta inúmeros limites. Uma das maiores dificuldades manifestadas se refere justamente à dificuldade em organizar o trabalho pedagógico, adequando-o aos conhecimentos dos alunos, ou seja, trabalhar com a/na diversidade. Aliás, esse é um desafio antigo da escola, seja ela ciclada ou não.

Essa é uma longa caminhada, porque transformar o modelo escolar vigente - a escola seriada - exige tempo e preparo dos profissionais envolvidos. Para auxiliar na organização do trabalho pedagógico da alfabetização, os estudos do letramento apresentam contribuiçóes ao ensino da leitura e da escrita no contexto escolar, entendendo a língua como parte do contexto social e apresentando-se como uma referência aos professores nessa nova organização da escola. 
A organização do ensino fundamental em ciclos no município de Campinas, estado de São Paulo, iniciou-se em 2006, inspirada nos estudos de Freitas (2003, 2004a, 2004b), bem como em experiências pioneiras, como as de Belo Horizonte e de Porto Alegre. Entre os princípios publicados $^{4}$ nos documentos, está o de que "Cada rede é única e, em Campinas, o Departamento Pedagógico (Depe) entendeu que as especificidades de nossa realidade nos levariam a construir um modelo próprio" (DEPE, 2010, p. 25). Tal proposta representa a busca de caminhos para que a comunidade escolar possa explicitar as finalidades educacionais de uma formação humana, que incorpore experiências socialmente significativas para as crianças.

De acordo com os materiais produzidos para o Pró-Letramento e para o Pacto Nacional pela Alfabetização na Idade Certa (ambos programas do MEC), considera-se como o ciclo da alfabetização - turmas de alunos com 6,7 e 8 anos de idade - os três primeiros anos do ensino fundamental destinado ao trabalho com práticas culturais específicas, como a aquisição da leitura e da escrita, o uso da oralidade, da gestualidade e de diversos gêneros de textos verbais e visuais. Segundo consta no material do Pró-Letramento, o "[...] objetivo é o de concentrarmos um esforço e atenção do aprendizado da língua escrita nesses anos decisivos da trajetória escolar de nossos alunos" (BRASIL, 2007b, p. 8).

De forma sintética, podemos dizer que, nos documentos publicados para orientar essa nova organização do trabalho pedagógico nas escolas, o objetivo no ciclo de alfabetização é, principalmente, que a criança leia e escreva diferentes textos, tendo em vista suas práticas sociais de uso da escrita: "Os textos, na escola, necessitam ser produzidos em variadas situações de usos reais da linguagem oral e escrita, privilegiando, desse modo, uma prática contextualizada de leitura e escrita" (BOSCO, 2007, p. 11). Nessa busca pela qualificação do aprendizado, o trabalho pedagógico precisa estar focado na criança sem perder o compromisso com a sua inserção sociocultural. Nessa perspectiva, os estudos de letramento contribuem para esse processo de formar a criança leitora e escritora, levando em conta suas práticas socioculturais.

\section{Letramento e ensino: relações}

Na contemporaneidade da segunda década do século XXI, nos deparamos com a realidade em que as sociedades, do mundo inteiro, estão cada vez mais centradas na escrita. Com a entrada definitiva da tecnologia 
A divulgação do conceito de letramento e o contexto da escola de nove anos...

no cotidiano das instituições e na vida privada, a escrita se faz mais presente. Porém, ensinar a ler e a escrever tem se revelado um processo com condições insuficientes para responder, adequadamente, às demandas contemporâneas. É preciso ir além da finalidade de se levar um sujeito a adquirir o domínio do código escrito. É preciso instaurar o ensino, tendo em vista os usos da leitura e da escrita nos diversos contextos sociais em que tais práticas acontecem. Nesse sentido, o conceito de letramento foi "[...] criado para referir-se aos usos da língua escrita não somente na escola, mas em todo lugar" (KLEIMAN, 2005, p. 5). O letramento perpassa práticas sociais para além do âmbito escolar, pois se centra nos empregos que cada sujeito faz da escrita nas variadas situaçóes sociais que demandam sua utilização.

$\mathrm{Na}$ medida em que o conceito de letramento é trazido e discutido no âmbito escolar, ele tem sido compreendido como indissociável do termo alfabetização, no sentido de ampliá-lo, de enriquecê-lo. Dito de outra forma, ensinar a ler e a escrever sempre a partir das condiçōes de uso reais da leitura e da escrita. ${ }^{5}$

Os estudos de letramento têm desencadeado algumas questôes acerca das práticas escolares de leitura e de escrita. Sua perspectiva tem penetrado nos cursos de formação inicial e continuada de professores, orientando propostas de atuação na escola que alertam para a importância de se levar em conta o letramento dos alunos. Segundo Kleiman (1995), a escola, a mais importante das agências de letramento, preocupa-se, fundamentalmente, com um tipo de prática: a de alfabetização. E, muitas vezes, esta é tratada como uma prática em si mesma, como um "processo de aquisição de códigos (alfabético, numérico), processo geralmente concebido em termos de uma competência individual necessária para o sucesso e promoção na escola” (p. 20).

Freire (2003) ao divulgar seu método de alfabetização, sempre fez a defesa do ensino da leitura e da escrita a partir da dinâmica concreta da vida dos homens. Em sua época, embora não fosse divulgada a noção de letramento, seus estudos deram bases para que a postura de reflexão frente à escrita considerasse seus usos na vida das pessoas. Vista nessa perspectiva, a alfabetização é entendida como uma das práticas de letramento, cuja tarefa deve ser desempenhada pela escola. Kleiman (2005, p. 12) afirma: "Se considerarmos que as instituições sociais usam a língua escrita de forma diferente, em práticas diferentes, diremos que a alfabetização é uma das 
práticas de letramento que faz parte do conjunto de práticas sociais de uso da escrita da instituição escolar".

Segundo Baptista (2010), o trabalho com a linguagem escrita desde a educação infantil precisa garantir o direito de a criança expandir seu conhecimento sobre o mundo, pressupondo situações nas quais possa compreender seu funcionamento no interior da cultura letrada: "A atuação da professora é, pois, fundamental para assegurar informaçôes, incitar a curiosidade e o desejo de conhecer, levar a criança a formular perguntas, a verbalizar e a formular suas hipóteses” (p. 10).

Para tanto, além de se garantir um ano a mais de escolaridade obrigatória com o ensino de nove anos, é preciso estabelecer o diálogo efetivo entre os diferentes segmentos da educação básica - educação infantil e ensino fundamental/anos iniciais e finais. Dentro dessa nova proposta de organização do ensino, é importante assegurar às crianças, na rotina de trabalho dos anos iniciais, o direito ao atendimento a suas características específicas, como: um espaço/tempo reservado ao brincar; um ambiente que estimule a leitura e a escrita, tendo em vista suas práticas sociais; a imaginação e a criatividade das crianças integrando o processo de aprender, de se desenvolver, de se conhecer e de se constituir como sujeito cultural e histórico.

$\mathrm{O}$ que dizem as professoras alfabetizadoras no contexto da escola ciclada e do ensino fundamental de nove anos?

Tomando o contexto da implantação do ensino fundamental de nove anos, juntamente com a implantação dos ciclos nas escolas municipais de ensino fundamental de Campinas, Tasca (2010) realizou uma pesquisa entre 2008 e 2010, com professores dessa rede de ensino. Assumiu a abordagem qualitativa e privilegiou uma aproximação do olhar desses profissionais sobre suas realidades. A pesquisa se concentrou em um grupo pequeno de docentes, tendo como objetivo aprofundar a compreensão de suas narrativas sobre suas práticas de trabalho junto aos alunos nos anos iniciais. ${ }^{6}$

Tal estudo teve como objetivo trazer para o foco da discussão os dizeres das professoras ${ }^{7}$ referentes às suas práticas alfabetizadoras no processo de implementação do ensino fundamental de nove anos em uma escola organizada em ciclos. Algumas questôes se destacaram no decorrer do trabalho de campo: 
A divulgação do conceito de letramento e o contexto da escola de nove anos...

- Sobre o novo $1^{\circ}$ ano do ensino fundamental, o que dizem as professoras: quais as possibilidades de trabalho, quais dificuldades encontradas?

- Sobre a escola organizada em ciclos: existem novas formas de organização do trabalho pedagógico? Como elas estão acontecendo?

- Nos relatos de trabalho sobre a prática alfabetizadora, que pistas aparecem sobre os processos de divulgação e de apropriação das perspectivas teóricas que circulam nos cursos de formação e nas escolas?

Foram realizadas entrevistas com quatro professoras que estavam atuando nos anos iniciais do ciclo de alfabetização: $1^{\circ}$ e $2^{\circ}$ anos. É importante ressaltar que se trata de professoras experientes e engajadas nas discussóes atuais. ${ }^{8}$ A faixa etária das professoras é distinta e, na ocasião da pesquisa, elas já tinham concluído vários cursos de formação.

A proposta do estudo era de compreender as inquietações das professoras frente à tarefa de alfabetizar, no processo da implantação da escola organizada em ciclos acoplada às mudanças que vêm ocorrendo no ensino fundamental. Um dos seus objetivos era o de registrar o movimento que tem acontecido nas escolas frente às mudanças curriculares e frente à divulgação de propostas de ensino nos cursos de formação que os professores têm frequentado em meio a tais mudanças.

A opção metodológica se deu pela História Oral (HO). De acordo com Guedes-Pinto (2002), a HO trabalha com a fonte oral, junto a outros corpus documentais, e tem como opção inscrever as versôes dos sujeitos comuns, anônimos, sobre o vivido e que, em geral, não estão presentes nos documentos oficiais. Ao tornar pública a pesquisa, a $\mathrm{HO}$ possibilita aos entrevistados que seus testemunhos sejam levados em conta pela história oficial, transformando seus depoimentos, por meio de sua análise e interpretação, integrantes da história do tempo presente.

Retomando o tema do estudo, com a implantação do ensino fundamental de nove anos, o município de Campinas precisou adequar-se ao modelo nacional, ao mesmo tempo em que iniciou a implantação dos ciclos. Junto disso ocorreu um intenso processo de circulação nas escolas de documentos oficiais sobre os ciclos, mas pouco ou quase nada se sabe sobre o que pensam disso os professores da rede municipal e como estão 
implantando suas práticas de trabalho. Para Amado (1995), pesquisadora da $\mathrm{HO}$, a fonte oral, materializada por meio das entrevistas, pode e deve ser utilizada como fonte de informação, como qualquer outro documento histórico. Os depoimentos orais podem fornecer pistas e informações preciosas, muitas vezes inéditas, impossíveis de serem obtidas de outro modo.

Portelli (1996), também pesquisador da $\mathrm{HO}$, chama a atenção para o fato de a fonte oral abrir e delinear um campo das possibilidades expressivas de cada narrador. Dessa forma, ouvir e registrar os relatos das professoras que vivenciam e constroem a história das práticas alfabetizadoras, no cotidiano do ensino fundamental da rede municipal de Campinas, constitui uma possibilidade para contribuir no processo de elaboração e de reconstrução dessas práticas.

As quatro professoras alfabetizadoras ressaltaram, em seus relatos sobre o trabalho na escola, que a rotina pedagógica não deve se restringir apenas ao ensino da base alfabético-ortográfica do sistema da língua e revelaram a importância de se trabalhar com os livros literários, com o intuito de que estes possibilitem aos alunos o contato com uma variedade de gêneros textuais.

A professora Maria ${ }^{9}$ nos relata que sempre foi apaixonada pelas histórias contadas pelo seu pai e por sua avó. Durante o período em que atuava como monitora na educação infantil, segundo ressalta, reviveu essa prática, pois contava muitas histórias para as crianças na creche:

Quando o professor faltava, nós, monitoras, assumíamos a sala. Sempre tinha essa rotina de história e música na educação infantil. Quando eu ingressei no ensino fundamental eu perdi esse elo, porque o professor de ensino fundamental não conta história e não canta. Hoje, aqui nesta escola alguns cantam, mas muito raramente. Inclusive, às vezes, quando eu vou contar histórias e cantar, tem professor que fala assim: "Eu estava lembrando o tempo da educação infantil". Eu fico pensando assim: Nossa! Se estiver se lembrando do tempo da educação infantil deveria fazer isso um pouquinho com a sua sala também.

Neste trecho da narrativa, os dizeres de Maria vão ao encontro das palavras de Kramer (2007), que ressalta a importância do diálogo entre as duas etapas da educação - educação infantil e ensino fundamental - com a proposta do ensino fundamental de nove anos.

Maria acrescenta que, atualmente, com a perspectiva dos estudos do letramento sendo divulgada no cotidiano escolar por meio dos cursos de 
A divulgação do conceito de letramento e o contexto da escola de nove anos...

formação, isso poderá ajudar os professores a superarem as práticas de ensino descontextualizadas, sem sentido, para os alunos que se alfabetizam. Ela mesma rememora sua prática pedagógica cotidiana de ler para seus alunos e a ressignifica, tendo em vista o conceito de letramento:

Minha prática diária é isso. É leitura pra essas crianças todos os dias. Tinha dia que, às vezes, eu não lia no começo da aula, tinha dia que eu lia depois do intervalo. Tinha época que eu lia depois que eles voltavam da educação física, pra acalmar [...]. Agora a gente tem uma prática de leitura na hora que eles estão mais sossegados. Leio todos os dias no início da aula. Temos posto essa leitura como prioridade na nossa sala de aula [...]. Algumas vezes, eu lia quando dava tempo ou lia pra acalmar, a leitura como uma coisa terapêutica, né? Agora não. Uso a leitura realmente para estar formando, tanto formando esse leitor como formando um escritor.

A partir desses dizeres, identificamos saberes e práticas de trabalho apropriados pelas professoras que apresentam relação com as propostas mais recentes divulgadas nos cursos de formação inicial e continuada de professores.

Maria relata que, após frequentar um curso específico de formação voltado à alfabetização, como o Letra e Vida, ${ }^{10}$ afirmou estar mais segura diante da tarefa de alfabetizar a turma que ingressou no $1^{\circ}$ ano, em 2007, e que continuou com ela no $2^{\circ}$ ano, em 2008:

Essa é a segunda turma de $1^{\circ}$ ano que eu pego. Então, trabalhar pensando no letramento das crianças trazendo mais leitura e não só aquela coisa do conteúdo, do conteúdo, do conteúdo, mas procurando ver realmente como essa criança está aprendendo [...]. As crianças aprendem mais tranquilamente, apesar de todas as crianças da sala ainda não estarem alfabetizadas, elas têm mais liberdade de chegar e conversar com você e perguntar, esclarecer as dúvidas. E você também. Como você não está preocupada só com conteúdo, você se preocupa com outras coisas e essas outras coisas ajudam você a trabalhar outros conteúdos, mas trabalhar os conteúdos não daquela forma de só jogar informação para a criança. Você vê como essa informação chegou e, se essa informação não chegou de uma forma como deveria chegar, você procura outras formas.

A professora Maria afirma que trabalha "pensando no letramento das crianças”. Apesar de não prosseguir explicando como faz isso na sala, mais adiante diz que não trabalha conteúdos "daquela forma de só jogar informação para a criança”. Apresenta, portanto, no seu dizer, uma crítica à educação 
bancária, tal como Freire (2003) apontava. Quando se refere à preocupação que tem em saber como a informação chegou até a criança, dá indícios de aproximação à perspectiva dos estudos do letramento, que são focados no contexto do aluno, na forma como ele acessa e se apropria do conteúdo.

Além da preocupação com os conteúdos curriculares, Maria afirma também que as crianças estão aprendendo mais tranquilamente. Podemos considerar que o fato de a professora vê-las mais tranquilas, pode ser atribuído, com efeito, ao ciclo de alfabetização destinar três anos para a consolidação do processo. Esse aumento de tempo para aprender pode ter significado para Maria uma flexibilização do processo que, até então, deveria ser de apenas um ano - a antiga $1^{\text {a }}$ série. Tal percepção reforça a visão de Freitas (2004a) sobre a importância de se reorganizar a escola procurando superar alguns de seus limites, como o uso do tempo.

A professora Rosa se confronta com essa nova organização da escola e afirma ter dificuldades em adequar seus métodos de trabalho às características de cada aprendiz, já que, com a implantação do ciclo de alfabetização, os alunos ficam agrupados por idade e não mais em séries:

Tenho alunos que estão comigo há dois anos e só agora que estão lendo. Agora que despertaram para leitura, mas graças a Deus, os que eram meus do ano passado estão todos lendo. Só tenho dois que entraram este ano que não leem, mas eu não culpo as crianças. Eu culpo a maneira que eles [ao se referir à Secretaria Municipal de Educação - SME] introduziram as crianças na escola. As crianças não podiam estar no $2^{\circ}$ ano porque não conheciam as letras e eu não tive tempo de ficar com elas como eu tive com os outros [...]. Eles saíram perdendo porque eles não acompanhavam os outros, porque o que você dava para os outros eles não acompanhavam e eu não tinha tempo de me dedicar a eles; de ir devagarzinho, paulatinamente, como eu fui com os outros. Eles ficaram com os prejuízos.

Identificamos neste depoimento a dificuldade da professora ao enfrentar a realidade da escola de nove anos do ensino fundamental. Os alunos que não frequentaram a educação infantil e foram integrados diretamente no $1^{\circ}$ ano vieram com uma bagagem completamente diferente dos que já estavam dentro do ensino fundamental. ${ }^{11} \mathrm{~A}$ professora diz, a respeito desse desafio: "provavelmente, teria que se ter organizado de forma diferente, na gestão do tempo".

Com a implementação da escola organizada em ciclos de aprendizagem e não mais em séries, na rede municipal de ensino de Campinas, 
A divulgação do conceito de letramento e o contexto da escola de nove anos...

observamos um movimento no intuito de superar a seriação a partir de mudanças curriculares que idealizam um ensino de melhor qualidade, como indicam documentos publicados pelo Depe.

Não podemos apenas ficar no campo das idealizações, pois o professor se queixa do modo como o ciclo foi implantado, conforme apontado nos dizeres de Rosa. Ela afirma ter se sentido despreparada para lidar com o novo conjunto de situaçóes apresentadas aos professores na sala de aula. Para Dalben (2009, p. 81) o professor se lamenta da ausência de condiçóes de trabalho quando, em uma sala repleta de alunos, precisa articular experiências de toda ordem, envolvendo problemas emocionais, afetivos, além da falta de conhecimento relativo ao seu conteúdo social, assim como de toda comunidade: "Manter interessados 30 jovens e crianças por mais de quatro horas por dia exige enorme criatividade pessoal e profissional".

A professora Maria se posiciona sobre a vivência que teve com outra forma de organização do trabalho pedagógico com as crianças em sua escola:

Acredito que esse trabalho de divisão de turmas tem nos ajudado bastante no que diz respeito, principalmente, àqueles que não estão alfabetizados. Todavia, é um incentivo novo aos alunos que já estão alfabetizados, pois dessa forma eles podem saber mais ou experimentar outros mundos. Minhas crianças que não gostavam de escrever textos, ou tinham dificuldade na produção escrita, passaram a se sentir mais à vontade diante de propostas de produção de textos. A participação deles foi bem melhor, pelo menos no quesito disposição para escrever.

Esse esquema de trabalho de dividir as turmas em determinados períodos para atividades diferenciadas vem sendo realizado em algumas unidades escolares, no ciclo de alfabetização na rede municipal de ensino de Campinas. A professora Karla também passou por essa experiência e relata que, entre os critérios usados para a divisão dos grupos no ano de 2008, estava o de se partir do conhecimento dos alunos, pois muitos ainda não conheciam as letras do alfabeto e, com a divisão das turmas, ficou mais fácil aproximar-se dessas crianças. Ela ressalta: "Foi possível perceber avanços em todos os grupos, mas conseguimos trabalhar de modo mais próximo de alguns alunos que mal conheciam as letras, e no final do ano já estavam formando palavras simples".

Além dessa atividade, Karla conta que procura trabalhar respeitando os diferentes conhecimentos de seus alunos no dia a dia da sala de aula de $1^{\circ}$ ano, seja em duplas ou em grupos com atividades diversificadas: 
Esses alunos que estão mais avançados a gente procura dar atividades pra que eles avancem mais e que possam também dividir esses conhecimentos com os alunos que também estão mais fracos [...]. São atividades que a gente vai direcionando o tempo inteiro, senta com eles (quando dá tempo de sentar).

Os dizeres de Karla apontam a necessidade de o professor acompanhar o que os alunos já se apropriaram sobre a língua escrita no processo de alfabetização e, também, mostram a interferência da professora ao juntar os alunos mais capazes com os que precisam de ajuda. Ela chama para si o papel de professora mediadora, como reconhece Fontana (2003), quando destaca que o professor é um mediador, intencional e explícito, entre o conhecimento e o aluno. Para a professora alfabetizadora, a questão da fluência na leitura e na escrita é apontada como um ponto primordial para que o aprendiz seja considerado plenamente alfabetizado. No contexto escolar, isso implica o uso de abordagens adequadas aos diversos textos que circulam em outras instituições sociais em que se concretizam as práticas socializadoras.

Muitos dos dizeres das professoras entrevistadas indicam que é necessário mediar as questôes direcionadas às práticas de letramento dos alunos, mas também enfatizam a necessidade de garantir o domínio do código linguístico, como discute a professora Cleide:

Letramento é fundamental, você saber dominar as informaçōes do uso etc., especialmente, num mundo globalizado é essencial, só que não dá pra esquecer que a escrita é uma convenção. Algo que se construiu historicamente e que demorou muito tempo para ser construída. [...] o homem demorou séculos até nós conseguirmos ter um código que unifica e universaliza algumas informações. E se você não ensinar, como fica o seu papel de professor? Para garantir um letramento, não precisa ser um professor, na verdade em casa, na internet, na lan house, no cinema, em qualquer lugar eles têm muito mais acesso a letramento que na sala de aula. $\mathrm{Na}$ rua ele tem jornais, revistas, outdoors, gibis, tem muito mais coisa do que nós temos aqui. Então, a gente precisa resgatar isso. Letrar é não deixar de fora a convenção e a convenção não é criada pelo aluno, pelo contrário, ela precisa ser ensinada. Se você não falar que o $m$ é antes do $p$ e do $b$, isso não vai sair de dentro dele sozinho, talvez um dia ele possa olhar e descobrir que $m$ é sempre antes do $p$ e do $b$. Então, tem algumas coisas que precisam ser ensinadas, se você não falar que nome se escreve com letra maiúscula, por isso, é um substantivo próprio, talvez ele não vá saber. É uma convenção, se institucionalizou, e um conteúdo historicamente construído, não se criou de uma hora para outra e deve ser ensinado. 
A divulgação do conceito de letramento e o contexto da escola de nove anos...

Este depoimento de Cleide nos fornece indicações de que ela está inserida em um campo discursivo divulgado pela academia. Por meio da narrativa dessa professora é possível notar seu conhecimento acerca de conceito de letramento, assim como identificamos sua assunção do papel de ensinar, como professora. Embora ela não cite teóricos, como o autor Bagno (2003), demonstra ciência a respeito das características da língua escrita - é uma convenção que precisa ser ensinada. Não basta a inserção nas práticas de letramento. Alfabetizar e ensinar as normas-padrão são fundamentais.

Rosa também ressalta essa preocupação ao nos contar como organiza a rotina no dia a dia com suas turmas:

Se você levar somente os textos: poesia, quadrinhas, cantigas para as crianças, você consegue alguma coisa, mas é uma coisa muito lenta. E o nosso tempo é pequeno. É muito curto pra alfabetizar essas crianças. Você está recebendo crianças que nunca fizeram $1^{\circ}$ ano. Outras, que saíram da creche para o fundamental e já querem que a criança leia no final do ano. Em cada conselho querem um texto das crianças. Para as crianças escreverem um texto é preciso que leiam, mas nem sabem ler ainda. Então, eu tento de todo jeito, e a única forma que dá certo, eu ensino o $a b c$, o $a$, o $b, \mathrm{o} c$ e vou ensinando ao mesmo tempo as palavras, vou associando as palavras com eles. Vou trazendo textos, vou trazendo músicas também, mas eu não deixo o método antigo: mostro que o $b \operatorname{com} a$ faz $b a, l \operatorname{com} a$ faz $l a, t \operatorname{com}$ $a$ faz $t a$. Não deixo de fazer isso.

Rosa enfatiza que faz uso de métodos mistos. Ao mesmo tempo em que diz usar o "método antigo", próximo das cartilhas, também afirma usar uma diversidade de gêneros textuais, como as leituras que circulam em suas aulas, caracterizando a presença dos princípios orientadores das propostas atuais de ensino em circulação nos cursos de formação de professores.

Cleide também comenta que procura alfabetizar seus alunos com leitura de textos e com produções escritas, mas quando encontra um aluno que demora a se alfabetizar, media o trabalho pedagógico enfatizando as sílabas, de um modo um pouco diferente do utilizado por Rosa:

Só que esse ano eu tive duas crianças que eu segui até o meio do ano, mais ou menos, tentando outras propostas que não fossem a silabação, que fosse algo mais tranquilo. Só que eles aprenderam somente quando eu abri mão das minhas verdades para tentar chegar à verdade deles. É lógico que mesmo a silabação não é dada daquela forma boba. Se eu quisesse que eles escrevessem, por exemplo, o meu nome, ou o nome de uma história, 
João e o pé de feijāo, por exemplo. Como é que se escreve o jo, professora? Ah, você sabe o ja de jardim que está escrito na lousa? Eu sei! Então como é que você acha que é o jo? Então, você segue e percebe que eles pegaram muito mais rápido. Porque pra eles foi muito mais difícil ver o todo e foi mais fácil quando ele começou pela parte [...]. Eu passei a andar segundo o meu aluno. São os alunos que têm que me dar os indicativos.

Karla, abordando outro aspecto da alfabetização, questiona, por exemplo, o fato de os cadernos de caligrafia terem sido eliminados do cotidiano escolar. Ela diz que, quando temos uma criança que tem a letra ilegível, o nosso papel como professora é mediar esse processo:

Você pode responder uma pergunta de interpretação de texto num caderno de caligrafia, numa linha de caligrafia. É duro ficar lá treinando $a a a, b b b b$, não tem sentido, mas se ele está usando a escrita, ele tem que aprender o traçado. A escrita cumpre a função dela quando comunica alguma coisa. Quando não entende o que está escrito: vai comunicar o quê?? Então, não se cumpriu a função dela.

Pelos dizeres de Karla, torna-se visível o embate entre as diferentes concepções de ensino que permeiam o cotidiano escolar e, muitas vezes, a predominância de uma acaba prejudicando os alunos ao não garantir, de fato, o acesso ao conhecimento.

Artes do fazer pedagógico frente à alfabetização e os estudos do letramento

No relato das professoras percebemos táticas mencionadas por elas, usadas em sala de aula para realizar o trabalho de ensino diante das novas demandas do cotidiano escolar. Certeau (1994) chama de táticas os modos de fazer criados pelos sujeitos ordinários para sobreviverem às obrigações diárias. As táticas são aproveitadas das ocasiōes do cotidiano.

A busca por superar os desafios da nova organização escolar pelas professoras pode ser entendida como uma de suas "artes de fazer" (CERTEAU, op. cit.). Suas táticas revelam habilidades para se saírem bem diante de uma normativa imposta. Essas profissionais criam, reelaboram, apropriam-se do tempo e do espaço escolar em que trabalham.

Nas falas das quatro professoras se destaca a preocupação em organizar o trabalho pedagógico, analisando o que seus alunos conhecem sobre a escrita 
A divulgação do conceito de letramento e o contexto da escola de nove anos...

e o que eles ainda precisam conhecer e aprender. As narrativas ressaltam os modos como a leitura e a escrita são apresentadas para as crianças, tendo em vista o planejamento do trabalho frente à nova organização escolar.

Seus dizeres apontam o desejo e o compromisso profissional em garantir aos seus alunos o domínio da base alfabético-ortográfica do sistema da língua. Maria, ao longo da sua narrativa, ressalta as contribuiçóes dos cursos de formação: em primeiro lugar, para assegurar aos seus alunos o direito de ler e de escrever e, em segundo lugar, para ter propriedades teóricas para sustentar sua prática diante dos colegas professores que a questionam. É possível identificar em seu dizer sua preocupação em relação aos embates entre as práticas de letramento autônomo - que visam o ensino de competências linguísticas (descontextualizadas) individuais no aluno - e as práticas de letramento organizadas para o trabalho pedagógico com o intuito de enriquecer e aprimorar aquelas que os alunos já conhecem, possibilitando assim a apropriação do sistema de escrita.

Muitos dos dizeres de Karla, de Maria, de Cleide e de Rosa apresentam um movimento de trabalho em sala de aula que parece vir da prática social para o conteúdo, cada qual a seu modo. Segundo Kleiman (2007), a partir do momento em que o letramento do aluno é definido como objetivo da ação pedagógica, o movimento será da prática social para o conteúdo, nunca o contrário, desde que o letramento do aluno seja o objetivo principal da ação pedagógica.

Também podemos perceber que as pesquisas baseadas nos estudos do letramento começam a repercutir, timidamente, nos dizeres dessas professoras alfabetizadoras sobre seu trabalho pedagógico. Tais dizeres apontam ${ }^{12}$ para conhecimentos adquiridos no processo de formação profissional, nas leituras de estudo, nas discussóes pedagógicas da escola ou mesmo por meio da leitura dos poucos documentos disponibilizados pelo Depe. Seus relatos revelam esforço à procura das maneiras de fazer. Certeau (1994) nos dá elementos para compreendê-las e destaca que essas são reinventadas a cada instante, revestidas de um saber próprio, fabricado nas suas operaçóes cotidianas.

De acordo com o que discutimos neste trabalho, a alfabetização possui características específicas, próprias da escola. Ampliar as práticas de letramento dos alunos, garantindo o domínio da leitura e da escrita, exige um trabalho sistematizado para que sejam considerados plenamente letrados. 
Finalmente, cabe aqui retomar um aspecto deste estudo. Utilizar a fonte oral, materializada pelas entrevistas, permitiu que os anseios profissionais das professoras alfabetizadoras fossem visibilizados no meio acadêmico. Tal fato possibilita aos pesquisadores e aos formadores de professores acompanharem como vem ocorrendo esse processo de elaboração e de compreensão do conceito de letramento frente às práticas alfabetizadoras.

Ao aceitar a participação neste estudo, cada professora teve a oportunidade de reelaborar suas experiências individuais - de leitura, da formação inicial e continuada, bem como as dificuldades de sua atuação docente. É possível afirmar, por meio da análise de suas narrativas, que as elaboraçóes acerca do ensino da escrita vão sendo construídas pelas professoras na tensão constitutiva entre os dizeres sobre suas práticas pedagógicas e os discursos acadêmicos divulgadores das teorias de alfabetização e do letramento.

\section{Notas}

1. Segundo a Resolução n. 3, de 3 de agosto de 2005, da Câmara de Educação Básica do Conselho Nacional de Educação (CNE/CEB), o termo pré-escola passa a denominar a faixa etária de 4 e 5 anos, os anos iniciais para a faixa de 6 a 10 anos de idade es anos finais para a faixa de 11 a 14 anos. Disponível em: :<www.mec.org.br>. Acesso em: 27 mar. 2009.

2. Por exemplo, o programa federal Pró-Letramento, de formação continuada de professores, criado em 2005 e voltado para a melhoria da qualidade do ensino-aprendizagem da leitura/escrita e da matemática, parte do pressuposto da escola organizada em ciclos.

3. Como, por exemplo: temos a escola Plural da Secretaria Municipal de Educação de Belo Horizonte, implantada a partir de 1995 e que foi a pioneira na proposta por ciclos no Brasil. A escola Cidadã da Secretaria Municipal de Educação de Porto Alegre passou, também, por um processo de reformulação de sua proposta, bem como da organização dos espaços e dos tempos, a partir de 1995, se configurando como uma escola organizada por ciclos.

4. Com o objetivo de reorganizar o tempo e os espaços escolares, o Departamento Pedagógico (Depe) do município de Campinas, em fevereiro de 2006, enviou às escolas documentos para orientações no momento do planejamento escolar, focando a instituição do ciclo inicial nas escolas municipais de ensino fundamental. Entre eles, temos: "Organização do trabalho didático - 2006" e o texto "Currículo de ciclo de alfabetização - texto base a partir do resgate das práticas de professores alfabetizadores”. E entre os anos de 2010 e 2011, foram publicadas ainda as "Diretrizes Curriculares da Educação Básica para o Ensino Fundamental e Educação de Jovens e Adultos - um processo contínuo de reflexão e ação".

5. Tanto o programa Pró-Letramento quanto os documentos do Departamento Pedagógico (Depe) de Campinas, já citados, incorporam essa diretriz dos estudos do letramento.

6. A pesquisa de mestrado da Tasca (2010), intitulada "Alfabetizar, letrar: práticas alfabetizadoras no contexto da escola organizada em ciclos”, foi defendida em 2010 na Faculdade de Educação da Universidade Estadual de Campinas.

Cad. Cedes, Campinas, v. 33, n. 90, p. 257-276, maio-ago. 2013

Disponível em <http://www.cedes.unicamp.br> 
A divulgação do conceito de letramento e o contexto da escola de nove anos...

7. A totalidade do grupo de professores era formada por mulheres.

8. Essas observaçốes foram feitas a partir do contexto do trabalho de campo da pesquisa.

9. Nome fictício da professora. Nenhuma delas foi identificada na pesquisa.

10. Os cursos do programa Letra e vida foram oferecidos pela Coordenadoria de Estudos e Normas Pedagógicas (Cenp) e coordenados pela professora Telma Weizs, uma das autoras responsáveis pela divulgação dos estudos de Emília Ferreiro no Brasil. É um curso apoiado na perspectiva teórica da psicogênese da escrita, muito valorizado pelos professores alfabetizadores.

11. Quando foi implantado em Campinas o $1^{\circ}$ ano do ensino fundamental de nove anos e a organização em ciclos, algumas crianças que não tiveram acesso à educação infantil foram matriculadas diretamente no $2^{\circ}$ ano por causa da idade, "pulando" o infantil.

12. Para um maior aprofundamento das observações e conclusões do trabalho de pesquisa, ver Tasca (2010).

\section{Referências}

AMADO, J. O grande mentiroso: tradição, veracidade e imaginação em história oral. Revista História, São Paulo, v. 14, p. 125-136, 1995.

BAGNO, M. A norma oculta. São Paulo: Parábola, 2003.

BAPTISTA, M.C. A linguagem escrita e o direito à educação na primeira infância. Belo Horizonte: Ceale/ UFMG, 2010. (mimeo.).

BOSCO, Z.R. Notas sobre a criança e a linguagem na escola. Campinas: Cefiel/Unicamp; SME/Depe, 2007. (versão preliminar).

BRASIL. Ministério da Educação. Secretaria de Educação Básica. Ensino fundamental de nove anos: orientaçóes para a inclusão da criança de 6 anos de idade. Brasília, DF: MEC/SEB, 2007a.

BRASIL. Ministério da Educação. Secretaria de Educação Básica. Pró-letramento: programa de formação continuada de professores dos anos/séries iniciais do ensino fundamental - Alfabetização e linguagem. Brasília, DF: $\mathrm{MEC/SEB}, 2007 \mathrm{~b}$.

CERTEAU, M. A invenção do cotidiano. Petrópolis: Vozes, 1994. v. 1.

DALBEN, A.I.L. Os ciclos de formação como alternativa para inclusão escolar. Revista Brasileira de Educação, Rio de Janeiro, v. 14, n. 40, p. 6682, jan./abr. 2009.

DEPE/CAMPINAS. O ensino fundamental de nove anos e o ciclo de alfabeti- 
zação: teorias e práticas. Campinas: Cefiel/Unicamp; SME, 2007. (Versão preliminar).

DEPE/CAMPINAS. Diretrizes curriculares para o ensino de lingua portuguesa no ciclo I do ensino fundamental. Campinas: SME/Depe, 2008.

DEPE/CAMPINAS. Ensaios: perspectivas e pressupostos para uma discussão curricular na Rede Municipal de Campinas; org. por Zelma Regina Bosco. Campinas: Set, 2009.

DEPE/CAMPINAS. Diretrizes curriculares da educação básica para o ensino fundamental e educação de jovens e adultos anos finais: um processo contínuo de reflexão e ação; org. e coord.: Heliton Leite de Godoy. Campinas: Millennium, 2010.

FONTANA, R.A.C. Como nos tornamos professoras? 2. ed. Belo Horizonte: Autêntica, 2003.

FREIRE, P. Pedagogia do oprimido. 36. ed. Rio de Janeiro: Paz \& Terra, 2003.

FREITAS, L.C. Ciclos, seriação e avaliação: confronto de lógicas. São Paulo: Moderna, 2003.

FREITAS, L.C. A avaliação e as reformas dos anos de 1990: novas formas de exclusão velhas formas de subordinação. Educação \& Sociedade, Campinas, v. 25, n. 86, p. 133-170, 2004a.

FREITAS, L.C. A “progressão continuada” e a "democratização" do ensino. In: VILLAS BOAS, B.M.F. (Org.). Avaliação: políticas e práticas. 2. ed. Campinas: Papirus, 2004b.

GUEDES-PINTO, A.L. Rememorando trajetórias da professora alfabetizadora: a leitura como prática constitutiva de sua identidade e formação profissionais. Campinas: Mercado das Letras; Faep/Unicamp; São Paulo: Fapesp, 2002.

KLEIMAN, A.B. Modelos de letramento e as práticas de alfabetização na escola. In: KLEIMAN, A.B. (Org.). Os significados do letramento: uma nova perspectiva sobre a prática social da escrita. Campinas: Mercado das Letras, 1995. 
KLEIMAN, A.B. Preciso "ensinar" o letramento? Não basta ler e escrever? Linguagem e letramento em foco. Campinas: Cefiel/IEL/Unicamp, 2005. KLEIMAN, A.B. O conceito de letramento e suas implicaçôes para a alfabetização. Campinas, Cefiel/Unicamp; SME/Depe, 2007. (Versão preliminar). KRAMER, S. A infância e sua singularidade. In: BRASIL. Ministério da Educação. Secretaria de Educação Básica. Ensino fundamental de nove anos: orientações para a inclusão da criança de 6 anos de idade. Brasília, DF: MEC/SEB, 2007.

PORTELLI, A. A filosofia e os fatos: narração, interpretação e significado nas memórias e nas fontes orais. Tempo, Rio de Janeiro, v. 1, n. 2, p. 5972, 1996.

TASCA, D.S.O. Alfabetizar, letrar: práticas alfabetizadoras no contexto da escola organizada em ciclos. 2010. Dissertação (mestrado em Educação) Faculdade de Educação, Universidade Estadual de Campinas, Campinas.

Recebido em 30 de setembro de 2012.

Aprovado em 11 de abril de 2013. 